\title{
Using the Network Metaphor to Design, Deliver, and Maintain a Construction Management Curriculum
}

\author{
Ihab M. H. Saad \\ Department of Construction Management, Northern Kentucky University, Highland Heights, KY 41099, USA \\ Correspondence should be addressed to Ihab M. H. Saad; saadil@nku.edu
}

Received 22 June 2015; Accepted 19 November 2015

Academic Editor: F. Pacheco-Torgal

Copyright ( 2015 Ihab M. H. Saad. This is an open access article distributed under the Creative Commons Attribution License, which permits unrestricted use, distribution, and reproduction in any medium, provided the original work is properly cited.

\begin{abstract}
Construction management programs accredited by the American Council for Construction Education (ACCE) are responding to new standards for accreditation, as the accreditation process itself is being changed to primarily focus on learning outcomes. These changes offer an opportunity and a challenge for existing programs to readjust and restructure to meet the increasingly changing expectations within the construction market. Using a network metaphor, with a critical path consisting of critical activities, activity codes, and constraints, can be a successful methodology to develop/align a construction management curriculum. As with any network, this approach can be used as both planning and control tool, being revisited regularly for further fine-tuning responding to the feedback resulting from assessment efforts to "close the loop." The resulting network can be presented in both tabular and/or graphical format highlighting the critical path and particular critical activities (learning concepts) within that path. Different resources can be applied to the schedule reflecting their commitment and availability limits (space, labs, computers, etc.).
\end{abstract}

\section{Introduction}

Construction education has witnessed several changes over the past decade responding to changing trends in the construction industry and the preponderance of relatively new developments in contracting, visualization, and sustainability, among other fields. The American Council for Construction Education (ACCE) is one of the primary bodies accrediting construction management programs mainly in the United States and a few programs overseas. Currently, there are 89 ACCE accredited programs including 3 Master's degrees, 74 Baccalaureate degrees, and 12 Associate's degrees, with an additional 13 candidates for the Baccalaureate degree and 6 candidates for the Associate's degree [1]. The maximum term of accreditation is 6 years, upon which a program's accreditation is sought to be renewed.

Construction management curriculum design and maintenance can follow different paths and structures and represent different focus areas ranging from engineering to business to art. Construction management programs are hosted in colleges of engineering, technology, business, architecture, and even sometimes agriculture, depending on the main focus of the program.
Replacing its curriculum topical content matrix that focused on the number of hours dedicated to material coverage, ACCE conducted a series of focus group meetings with stakeholders from the construction industry to identify program learning outcomes. These learning outcomes were based on what the stakeholders considered as the most important skills a graduate from a construction management program must have. The selected twenty ACCE Program learning outcomes are listed hereunder:

(1) Create written communications appropriate to the construction discipline.

(2) Create oral presentations appropriate to the construction discipline.

(3) Create a construction safety plan.

(4) Create construction project cost estimates.

(5) Create construction project schedules.

(6) Analyze professional decisions based on ethical principles.

(7) Analyze construction documents for planning and management of construction processes. 
(8) Analyze methods, materials, and equipment used to construct projects.

(9) Apply construction management skills as an effective member of a multidisciplinary team.

(10) Apply electronic-based technology to manage the construction process.

(11) Apply basic surveying techniques for construction layout and control.

(12) Understand different methods of project delivery and the roles and responsibilities of all constituencies involved in the design and construction process.

(13) Understand construction risk management.

(14) Understand construction accounting and cost control.

(15) Understand construction quality assurance and control.

(16) Understand project control processes.

(17) Understand the legal implications of contract, common, and regulatory law to manage a construction project.

(18) Understand the basic principles of sustainable construction.

(19) Understand the basic principles of structural behavior.

(20) Understand the basic principles of mechanical, electrical, and plumbing systems.

Program design and delivery must follow a wellchoreographed and scheduled effort, to deliver the expected program learning outcomes within a specified number of prescribed student credit hours, varying from one program to another, with a median of 120 credit hours. The challenge of designing and continuous updating of such programs to keep their relevance necessitates a detailed planning effort similar to the effort needed for designing and delivering a construction project within its triple constraint: scope, time, and quality. This paper introduces the metaphor of a construction schedule in the design and maintenance of a construction management curriculum.

\section{Curriculum Management versus Time Management}

Previous efforts have been presented aiming at utilizing project management tools and techniques in the process of preparing for a program accreditation site visit [2] and for distance education [3], or deriving construction management curriculum content from industrial workflow processes [4], as well as developing an integrated model for construction management education using a structured approach [5]. Following in this approach, the purpose of this paper is to present a planning methodology to design, align, and assess a construction management program using the metaphor of a construction project schedule in the form of a network. Through the paper, comparisons will be drawn between the structured efforts to design and deliver a construction management curriculum and the sequential steps followed to develop a network schedule for a construction project.

The Project Management Institute (PMI) is an international entity interested in the propagation of the project management culture and best practices among project management stakeholders. It has complied a comprehensive body of knowledge on managing projects in general, including construction project, and breaks down the project management methodology into ten interrelated, yet distinguishable, areas including scope management, time management, cost management, and risk management. According to the PMI, managing project time consists of six consecutive steps leading to the development and management of a time schedule [5]. These six steps, in order, are as follows:
(1) Activity definition.
(2) Activity sequencing.
(3) Activity resource estimating.
(4) Activity duration estimating.
(5) Schedule development.
(6) Schedule control.

2.1. Activity Definition. Huba and Freed [7] identify the sequence of designing and delivering course outcomes as a pyramid, with the wide base consisting of the broad outcomes expected of all students of an academic institution, then working backward to design the outcomes of an academic program within the institution, and finally the design of the course objectives and outcomes leading to the achievement of the aforementioned two sets of outcomes. This concept can be expanded to include two additional and finer layers: the design of learning outcomes for a module within a course and finally the design of learning outcomes of a lecture or lesson within that module. These learning objectives and outcomes can be represented by the activities in a network representing the full curriculum design and delivery (the project).

One of the primary tools used for defining the project activities is a technique called project decomposition, which can be implemented through a tool known as the Work Breakdown Structure (WBS). The WBS breaks down the project along some logical lines into subprojects, followed by primary packages, and ending with work packages. These work packages represent the step prior to the project activities. The WBS development usually follows a rule of thumb of 1-5-5-5-5, which entails that each level should be broken down to about 5 subsequent sublevels, and so on. The number 5 is not carved in stone, and according to best practices it can range between 3 and 7. A construction project WBS can be broken down by package (structural, mechanical, electrical, landscaping, finishes, etc.), by location (building 1, building 2, etc.), by responsibility (self-performed, subcontracted, etc.), or by any other meaningful order. At the lowest level of the WBS, the work packages will almost be the same regardless of the top breakdown levels. Following the same procedure, a construction management curriculum can be broken down in different ways including the major curricular content (e.g., 


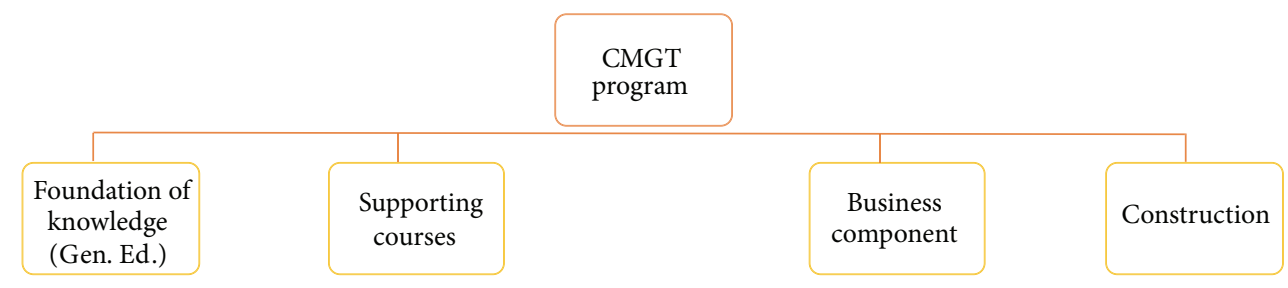

Figure 1: Level one breakdown.

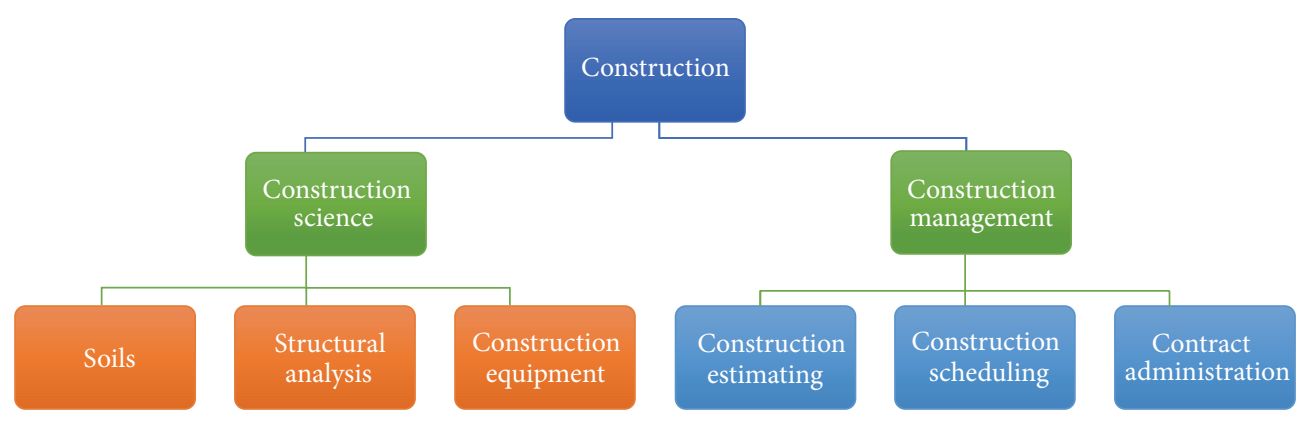

FIgURE 2: Levels 2 and 3 breakdowns.

foundation of knowledge or general education, supporting courses, business component, and construction classes). Subsequently, the construction classes can be broken down into construction science and construction management subgroups, which can be further defined by the courses in each of the subgroups. Figures 1 and 2 reflect this breakdown for the first 3 levels of the curriculum WBS. Each of these work packages (courses) can be further broken down to reach the level of activities or curriculum topical content or learning objectives to be covered in a course through a lecture of a group of lectures forming a module within the course.

Alternatively, the construction management curriculum can be broken down according to the Bloom's taxonomy of learning [8], which aims to measure the graduating student's capabilities of remembering, understanding, applying, analyzing, evaluating, and creating different content through the core subjects they have learned in the program. The six levels adopted by ACCE in assessing the program learning outcomes include, in a descending order, the following:

(1) Create.

(2) Evaluate.

(3) Analyze.

(4) Apply.

(5) Understand.

(6) Remember.

For baccalaureate programs, the first five levels have been selected for assessment, whereas the learning outcomes of a 2-year program may include the lowest level; remember that. However, this level is acceptable as an interim objective, especially for introductory classes.
Each learning outcome was assigned to one or more classes, with three different levels of coverage including introduction, reinforcement, and assessment. Figure 3 reflects a WBS based on the 6 Bloom's levels.

Activities can be distilled from these work packages, with different attributes and codes assigned to them for further selection, sorting, and filtering. These activity codes could be the course number, semester offered, responsible faculty, method of delivery, and mastery level on the modified Bloom's taxonomy scale [9]. Table 1 represents activities within a scheduling course with the activity codes based on Bloom's.

This activity definition will be the essential foundation upon which the schedule (the curriculum) will be constructed. It will also help with developing reports about adequacy and completeness of coverage of different subjects within the curriculum and the proper sequencing of delivery leading to the assignment of prerequisite and corequisite courses within the program.

2.2. Activity Sequencing. Similar to schedule development, the sequencing of topics and subjects within a curriculum has to be conducted following a logical order, taking into account the level of depth of coverage, the prerequisites and corequisites, and the gradual development in topic coverage. This coverage can escalate gradually from a basic introduction to reinforcement in different courses and finally to assessment of the delivered concepts through multiple modes of assessment that cater to the level of depth of coverage. Similar to their use in project schedules, constraints may play a role in the sequencing of activities. Some of these constraints are rigid constraints, implying one method of delivery or one particular mandatory order, whereas other constraints may reflect a "soft" order, implying that it is 


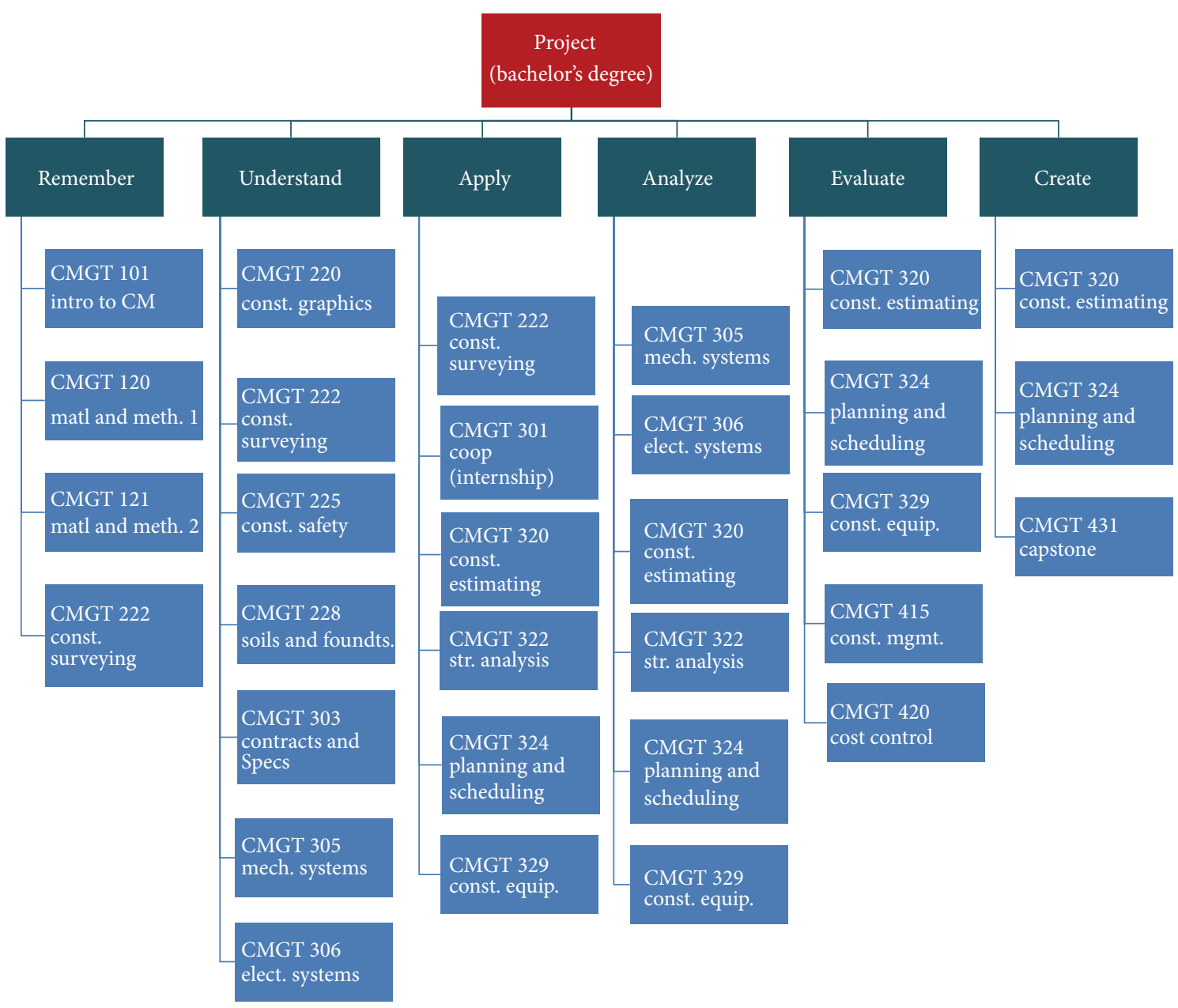

FIGURE 3: WBS based on Bloom's taxonomy.

the preferred order, not necessarily a mandatory order. Logical order would put a blueprint reading class as a predecessor for an estimating or scheduling class and would necessitate that a capstone class (if it exists within the curriculum) must appear at the end of the logical chain of activities (i.e., the critical path). Mechanical and electrical classes may be introduced at different locations within the schedule, and the order between these two classes reflects the flexibility that can exist in the sequencing of activities. Rigid constraints may include the class size, the frequency of offering classes, the availability of instructors, and space limitations. Figure 4 reflects an example of a sequencing showing predecessors and successors within a program delivery, which can be colorcoded to reflect a "critical path" leading to graduation within a prescribed time period (4 years typically).

2.3. Activity Resource Estimating. Resources needed for successfully delivering a construction management program, or any educational program for that matter, include primarily 3 essential ones: students, facility, and faculty. Fluctuation in the availability of any of these three essential (driving) resources may result in a disruption of the activity sequence and the timely completion of the project (timely graduation of students). Availability limits and constraints on these resources (minimum class size, maximum class occupancy, and availability of qualified faculty) have to be taken into consideration as limiting factors or boundary conditions. These limits and their impact on the schedule may go into an iterative process until a point is reached where they will not have a negative impact on the sequencing. As with any construction schedule, the limits of availability of the driving resources will be among the rigid constraints to be considered.

2.4. Activity Duration Estimating. Once the activities have been identified and defined and put into a logical order and resource availability is determined, the next step is to determine the duration for each activity. In a construction schedule, the simple equation of $(Q / P)$ is used to calculate the duration, where $Q$ represents the amount of work to be done and $P$ represents the production rate or productivity of the slowest resource involved in the activity. The duration of modules and submodules in a class will depend on the amount of material to be covered, the speed of absorption 
TABLE 1: Activity list for a planning and scheduling course.

\begin{tabular}{|c|c|c|}
\hline & & Topic \\
\hline \multirow{4}{*}{ Remember } & 1 & Types of scheduling techniques \\
\hline & 2 & Steps of time management \\
\hline & 3 & \\
\hline & 4 & \\
\hline \multirow{8}{*}{ Understand } & 1 & Types of constraints \\
\hline & 2 & Differences between different scheduling techniques and the suitability of each \\
\hline & 3 & Logic of CPM calculations \\
\hline & 4 & Types and physical meaning of float \\
\hline & 5 & Time/cost tradeoff \\
\hline & 6 & Types of delays \\
\hline & 7 & Difference between deterministic and probabilistic modes of scheduling \\
\hline & 8 & Activity codes and project filters \\
\hline \multirow{7}{*}{ Apply } & 1 & Develop a simple work breakdown structure \\
\hline & 2 & Perform forward and backward pass calculations for a network \\
\hline & 3 & Perform line of balance calculations \\
\hline & 4 & Perform earned value calculations \\
\hline & 5 & Perform PERT calculations \\
\hline & 6 & Use computer software to solve networks \\
\hline & 7 & \\
\hline \multirow{4}{*}{ Analyze } & 1 & Perform network updating and compare project dates \\
\hline & 2 & Select activities for compression and perform time compression \\
\hline & 3 & Review cash flow options and suggest solutions \\
\hline & 4 & \\
\hline \multirow{4}{*}{ Evaluate } & 1 & Evaluate the impact of project delays on project outcomes (LD, etc.) \\
\hline & 2 & Devise alternative plans to restore project progress \\
\hline & 3 & Calculate earned value variances and indices and provide explanations \\
\hline & 4 & \\
\hline \multirow{6}{*}{ Create } & 1 & Create a work breakdown and activity list for a project \\
\hline & 2 & Calculate activity durations based on resource requirements and project scope \\
\hline & 3 & Create a computerized schedule for a project \\
\hline & 4 & Develop project reports for selection and sorting of activities \\
\hline & 5 & Perform project comparisons based on progress updates \\
\hline & 6 & \\
\hline
\end{tabular}

of the new materials by the students, and the impact of the delivery mode: face-to-face, hybrid, online, or flipped class. Abeysekera and Dawson [10] defined flipping the classroom as the concept of moving most information-transmission teaching out of class, while using class time for learning activities that are active and social, and requiring students to complete pre- and/or postclass activities to fully benefit from in-class work. This approach may result in an increase in productivity, thus shortening the activity duration or allowing for more materials to be covered in the same amount of time.

2.5. Schedule Development. Developing the schedule entails, among other things, performing its calculations to identify its critical path and the amount of flexibility, or float, in its noncritical activities. The critical path calculations are conducted in two main, and opposite, calculations: the forward pass and the backward pass. The forward pass starts from the beginning of the network, adding durations while moving from left to right, until the end of the network is reached. This calculation determines the early dates of the different activities. The backward pass, on the other hand, starts from the end of the network, moving from right to left, subtracting the activity durations till the beginning of the network is reached, thus determining the late dates for the different activities. A comparison between the dates obtained from the forward pass and the backward pass yields the critical activities, which are defined as the activities with no flexibility, or float, and for which any delay will delay the completion of the whole project.

Similarly, curriculum design, delivery, and assessment will constitute the critical path calculations with a forward pass and a backward pass. The design and fitting of learning objectives within a limited number of credit hours (120 in most cases) represent the forward pass, and the assessment of the program upon its delivery and completion to measure 


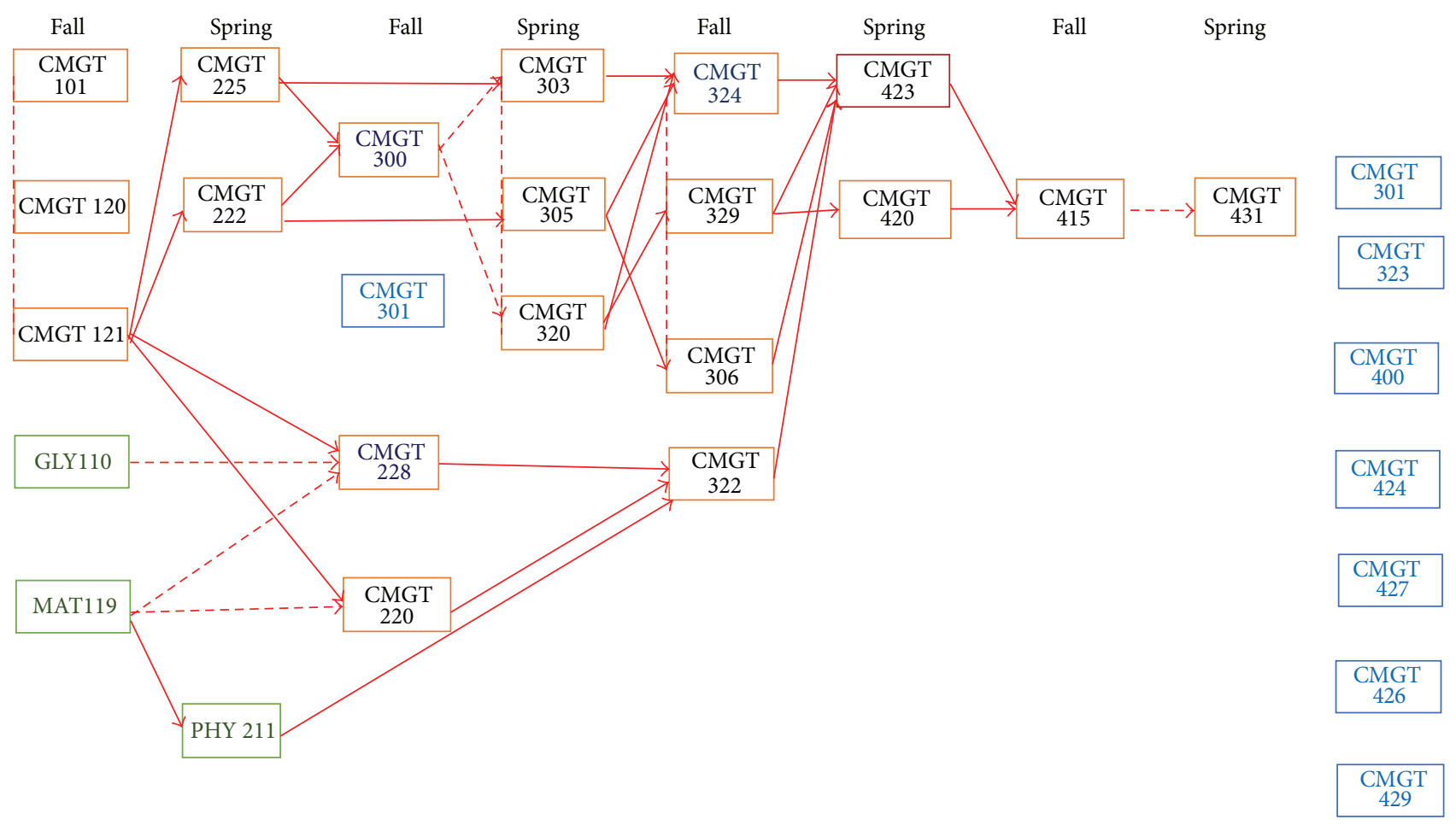

Figure 4: Activity (class) sequence.

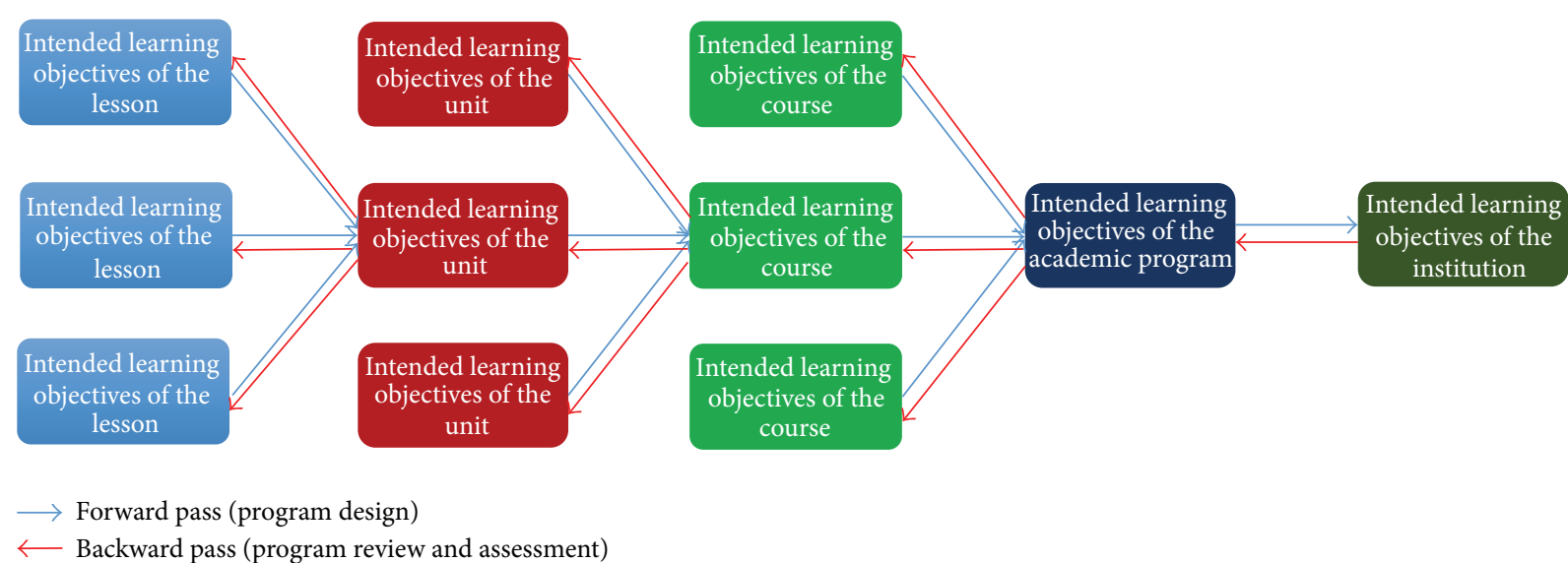

Figure 5: Delivery (forward pass) and assessment (backward pass) cycles.

its learning outcomes represents the backward pass. Closing of the loop, that is, ensuring that the intended objectives were delivered and assessed, thus becoming measurable outcomes, represents the calculations of the critical path. Figure 5 graphically represents one cycle of the process, with the intended learning outcomes forming the forward pass and the achieved results representing the backward pass. Validation of the achievements was conducted using exams, projects, and a comprehensive third party test in the form of the Associate Constructor exam provided by the American Institute of Constructors.
2.6. Schedule Control. Major curriculum changes necessitated by observed and measured weaknesses or deficiencies represent elements of schedule control. Observed deviations (assessed weaknesses) represent iterations to the network calculations, requiring further revisions of the original plan (updates), followed by additional delivery (replanning or revised plan) and continuous assessment. Additional curriculum changes necessitated by new developments in the field (introduction of new technologies and adoption of new concepts) may require a major overhaul of the schedule, resulting in the creation of a new baseline with a new scope, 
followed by another cycle of assessment and control. This process represents the continuous improvement in curriculum delivery based on documented feedback from the different stakeholders.

\section{Conclusion}

Responding to the new accreditation standards adopted by the American Council for Construction Education, construction management programs must focus on the learning outcomes achieved across the program rather than the number of hours spent in delivering different topics. The network metaphor can be used to develop, deliver, assess, and update a construction management curriculum. Levels of knowledge acquisition and retention can be assigned based on Bloom's taxonomy of educational objectives to gauge the success of the program in delivering its intended learning objectives. Visual presentation of the curriculum as a network schedule helps identify proper sequence for classes and inform the stakeholders of the information discussed therein. Activity codes and resources can be added to the schedule to determine its feasibility. To maintain and update the plan, a schedule management plan must be devised to deal with curriculum revisions, updates, and major changes responding to the results of regular program assessment.

\section{Conflict of Interests}

The author declares that there is no conflict of interests regarding the publication of this paper.

\section{References}

[1] American Council for Construction Education (ACCE), 2014, http://www.acce-hq.org/accredited_programs/category/baccalaureate-programs/.

[2] A. B. Badiru, J. M. Slagley, and D. A. Smith, "Project management application for engineering program accreditation preparation," Journal of Professional Issues in Engineering Education and Practice, vol. 136, no. 1, pp. 39-47, 2010.

[3] A. B. Badiru and R. R. Jones, "Project management for executing distance education programs," Journal of Professional Issues in Engineering Education and Practice, vol. 138, no. 3, pp. 154-162, 2012.

[4] J. J. Hannon, "Construction management program curriculum content derived from industrial workflow processes," in Proceedings of the ASEE Southeast Section Conference, Tuscaloosa, Ala, USA, April 2006.

[5] D. McDaniel, "Developing an integrated curriculum model for construction management education," Online Journal for Workforce Education and Development, vol. 1, no. 3, 2005.

[6] Project Management Body of Knowledge (PMBOK), Project Management Institute, 5th edition, 2013.

[7] M. E. Huba and J. E. Freed, Learner-Centered Assessment on College Campuses: Shifting the Focus from Teaching to Learning, Allyn \& Bacon, Needham, Mass, USA, 2000.

[8] B. S. Bloom, M. D. Engelhart, E. J. Furst, W. H. Hill, and D. R. Krathwohl, Taxonomy of Educational Objectives: The Classification of Educational Goals, Handbook I: Cognitive Domain, David McKay Company, New York, NY, USA, 1956.
[9] D. R. Krathwohl, "A revision of bloom's taxonomy: an overview," Theory into Practice, vol. 41, no. 4, pp. 212-218, 2002.

[10] L. Abeysekera and P. Dawson, "Motivation and cognitive load in the flipped classroom: definition, rationale and a call for research," Higher Education Research \& Development, vol. 34, no. 1, 2015. 

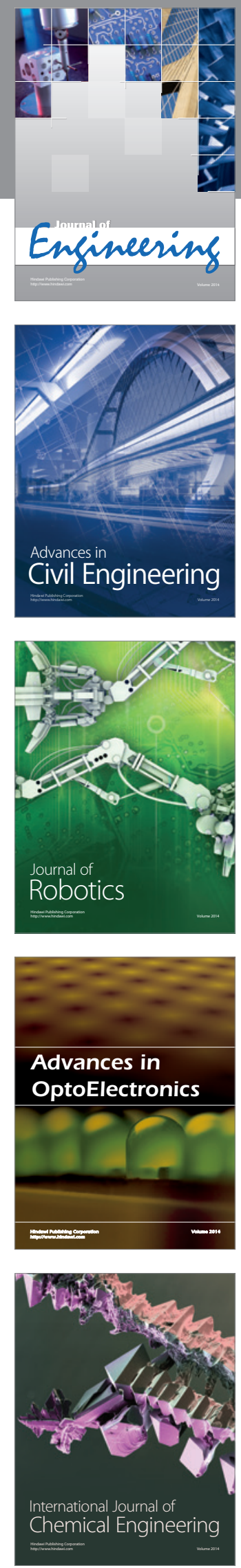

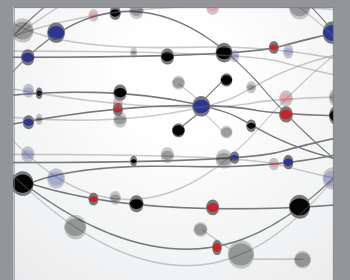

The Scientific World Journal
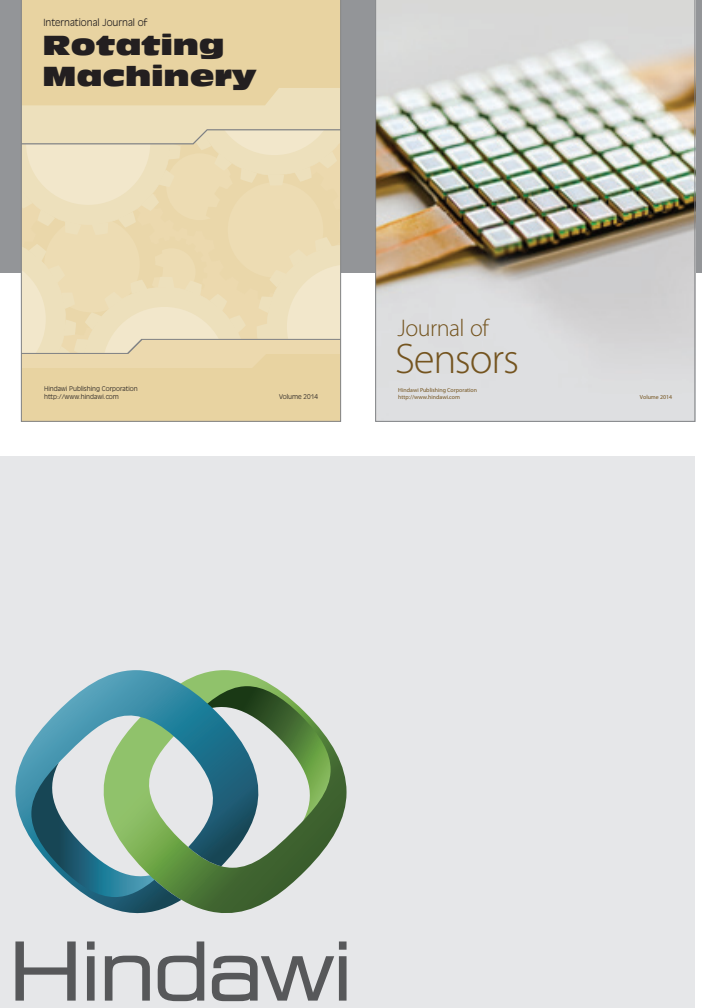

Submit your manuscripts at http://www.hindawi.com
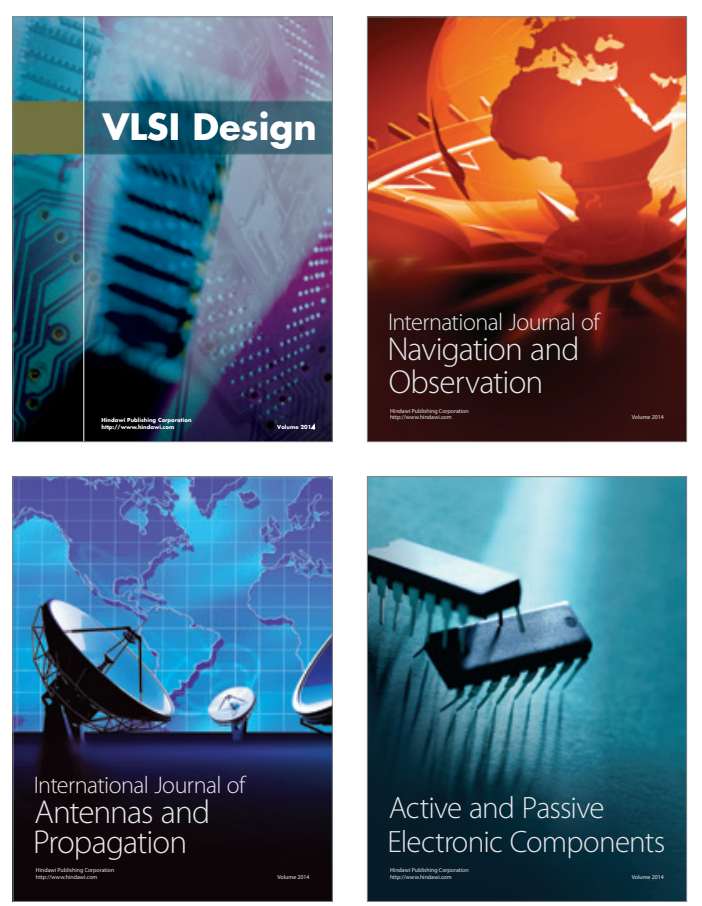
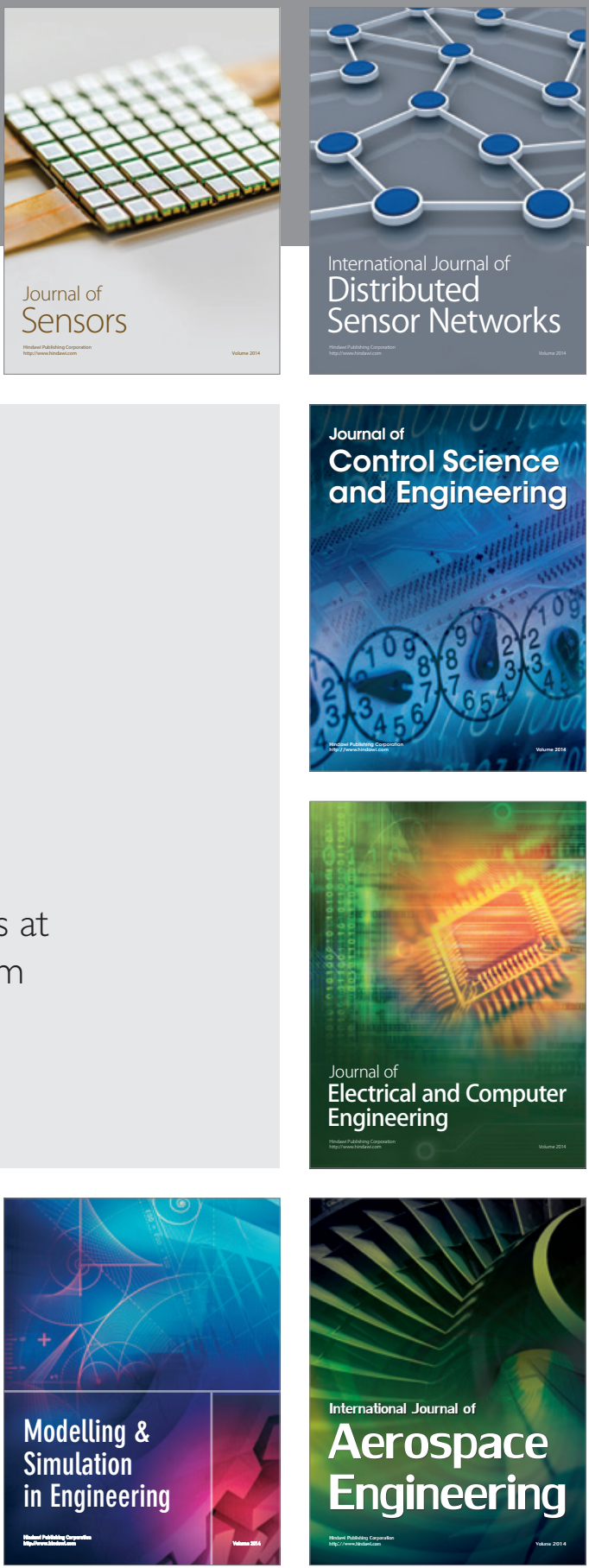

Journal of

Control Science

and Engineering
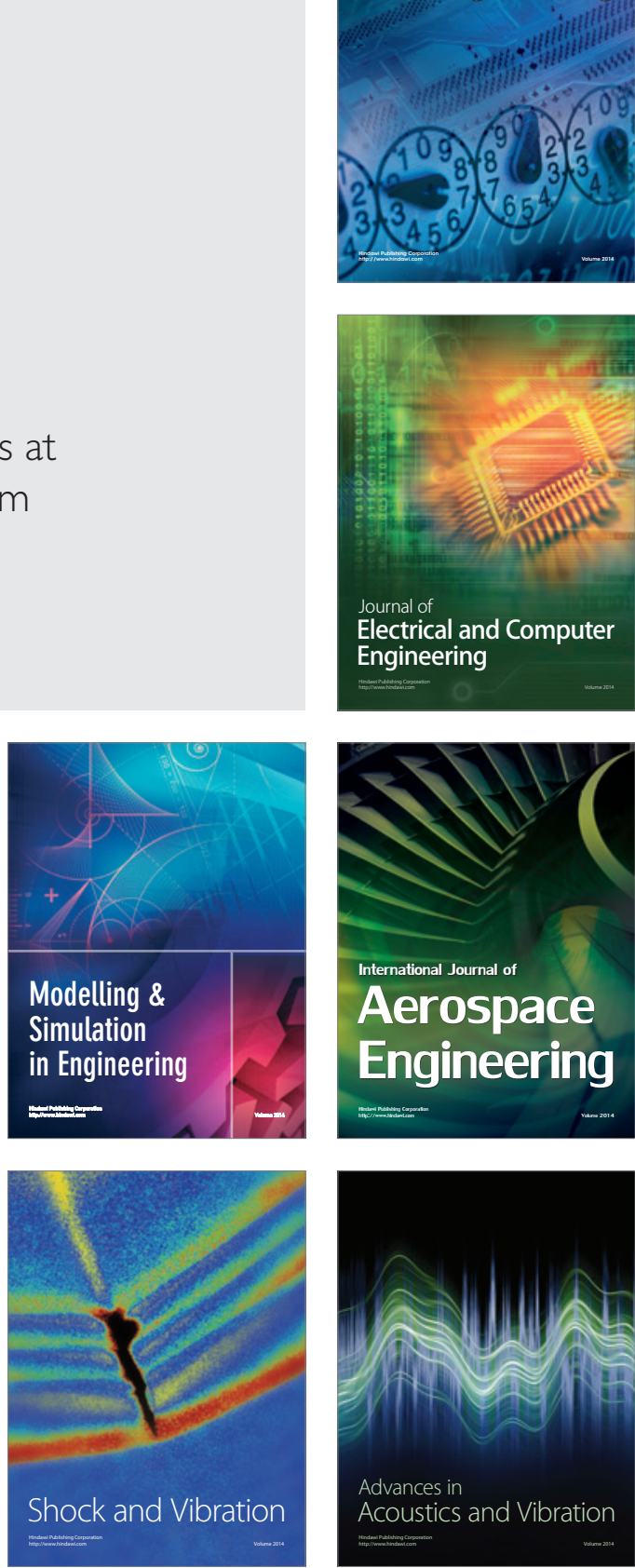